\title{
10. Ropivacaine toxicity after surgical wound local infiltration in a patient with renal failure
}

\author{
Chara Savva $^{1}$, Efthimia Kalliontzi ${ }^{1}$, Eleni Papaioannou ${ }^{1, *}$, Dimitrios Karousos ${ }^{1}$, Aikaterini Liosi ${ }^{1}$, Despoina Danassi ${ }^{1}$, \\ Aikaterini Lampadariou ${ }^{1}$ \\ ${ }^{1}$ Department of Anaesthesiology, Pain and Palliative Care, «Laiko» General Hospital of Athens, Athens, Greece. * \\ eleni_papaioannou@hotmail.com
}

Aim of study: is to present case of ropivacaine toxicity after surgical wound infiltration.

Case report: Female 49-year-old patient, with chronic renal failure, underwent kidney transplantation from living donor. Her medical history, revealed hypertension. No known allergies were mentioned. She had had laparoscopic cholecystectomy and placement of peritoneal catheter. She also had dental surgeries under local anaesthetic without any complications. Preanaesthetic examination was normal, apart from the expected.

Patient was intraoperatively haemodynamically stable. During reperfusion, there was no remarkable haemodynamic instability (Blood Pressure (BP): 140/70 mmHg, Heart rate (HR): $62 \mathrm{bpm}$ ). Before closure, surgical wound was infiltrated with ropivacaine, $0.375 \% 20 \mathrm{~mL}$. 18 minutes later, BP and cardiac output-CO were abruptly decreased (mean BP - MBP $<55 \mathrm{mmHg}$ and $\mathrm{CO}$ dropped from 7.1 to $2.5 \mathrm{~L} / \mathrm{min}$ ). H1, H2 receptor antagonists and crystalloids were administered iv, and noradrenaline infusion maintained MBP between $70-80 \mathrm{mmHg}$. Cardiac ultrasound was normal and troponin count was negative. Surgical wound was reopened for investigation, which did not reveal haemorrhage. One hour postoperatively, patient was stabilized, extubated, and was transferred to ICU for observation, without any sympathokinetic drugs' infusion. Post-awakening, she complained about tongue numbness. Two months later, as renal function was normal, she was scheduled for peritoneal catheter removal. Ropivacaine $0.357 \% 10 \mathrm{~mL}$ was administered for wound infiltration. Milder decrease in BP and CO 20 min later, was immediately managed with noradrenaline iv infusion. Post-extubation, the patient reported metallic taste that raised furthermore initial suspicion of ropivacaine toxicity.

Conclusion: Ropivacaine wound infiltration has been probably the reason of decrease in MBP and CO (local anaesthetic toxicity) in this case. International literature review was not conclusive, apart from cases of prolonged ropivacaine duration, in renal failure patients $[1,2]$. Further observation of similar cases is necessary to confirm ropivacaine toxicity after wound local infiltration.

\section{References}

[1] Jokinen MJ. The pharmacokinetics of ropivacaine in hepatic and renal insufficiency. Best Practice \& Research Clinical Anaesthesiology. 2005; 19: 269-274.

[2] Pere PJ, Ekstrand A, Salonen M, Honkanen E, Sjövall J, Henriksson J, et al. Pharmacokinetics of ropivacaine in patients with chronic renal failure. British Journal of Anaesthesia. 2011; 106: 512-521. 